\title{
The Business Intelligence and Its Influence on Decision Making
}

\author{
Andrés R. Negro \\ University of the Pacific \\ Keiser University \\ Ron Mesia \\ Florida International University
}

\begin{abstract}
Nowadays, organizations seek to be within the framework of the fourth industrial revolution and build the competitive pillars of today's business based on a different value proposition that satisfies customer needs based on business intelligence. The purpose of this paper is to share an author's review based on diverse points of view whose convergence focuses on the importance of internal and external data collection, which after an evaluation and validation process, becomes specialized information that is integrated as knowledge and influence in decision making.
\end{abstract}

Keywords: business intelligence, integration - influence, decision making

\section{INTRODUCTION AND PURPOSE OF THE CONCEPTUAL REVIEW}

Obtaining and handling different information sources by global organizations, supported by vast amounts of data to be analyzed through technological tools to turn them into useful and accurate information, is one of the tremendous current challenges within the continually changing business enviroment.

Information is subsequently based on the application of a specialized analysis that collaborates with effective business decision making. This is a priority responsibility of an organization (Gartner, 2013), and at the same time, is a process that involves complexity given a large amount of all kinds of accurate and speculative information being generated.

Due to this, the conversion of information and data occurs, through technological tools, inaccurate and reliable indicators that generate results used in decision-making (Miret and Conesa, 2014). The decision-making process depends on the technology decisional instrumental support and technological process tools that provide a viable and agile scenario to store, refine, and analyze data that are converted into elaborate and useful information.

The developed information provides executive knowledge applicable "to the mental process in which it is possible to identify the actions that will be taken to achieve a feasible dilemma in order to achieve an objective" (Vidal, 2012 p.137), which is called the action of decision-making. Business Intelligence (BI) is one of the technological tools or methodology that supports the conversion of information contributing to organizational decision-making. 
The purpose of this paper is to undertake a documentary review of specialized literature that will determine the level of interrelation and direct connection of influence between business intelligence and organizational decision-making, for which a research question will be defined that circumscribes the theoretical review work that defines the result of the article to a central argument.

For this purpose, the research question is raised as an argument and purpose of the paper: Is there any influence of the business intelligence technological tool in the organization's decision-making process? This question will define the findings of the review, as mentioned above, and it will provide a central focus on revised academic inputs that contribute to forging future mixed (quantitative and qualitative) research concerns.

Future research should focus on business intelligence amalgamating interaction, and direct influence with the decision-making act within the organizational environment. Decisive acts of an argumentative line are the "parametric theory of decision" mentioned by Aguiar (2004) cited by Páez (2015). A theory which will be developed in the section regarding the theoretical framework of decision making, after the review of the paradigms that compose such theory, to share the rationality approach of decision making, which will bring the development of work towards the theoretical aspect as a bridge between decision making and business intelligence.

\section{STRUCTURE OF THE REVIEW}

The paper will be divided into four sections: the first will introduce the theoretical framework that supports the concept of decision making through academic theories, and then align it with the methodology of business intelligence. Then there will be a literature review where the previous scholarly opinion on the existence of interrelated and influential links between both business concepts will be shared. The third section will share the particular analysis of this article's author, in order to then present the convergences or discrepancies of the review that will guide towards the recommendations and conclusions of the theoretical review.

\section{THEORETICAL FRAMEWORK}

\section{Theoretical Framework of Decision Making}

The theoretical framework will be focused on the individual responsibility of the global organization executive who has the decision-making autonomy that will determine the success or failure of the organization he or she manages (Vidal, 2012). This aspect is framed in the parametric theory of the decision, which in the words of Aguiar (2004), cited by Páez (2015), is developed within "a preestablished context" (p.856).

Such a pre-established context is defined based on a psychological environment of decision making by the individual. They have three influence approaches or paradigms: "the regulatory, the prescriptive and the descriptive" (Paez, 2015, p.857), strategies and models that among themselves have significant approximations and differences within the decision-making environment.

\section{Regulatory Paradigm}

In essence, the name shows the practical and structured aspect of a decision process, which is close to that provided by Taylor (2013), in the function of the "rationality" criterion. This criterion explains the essence of consistency of the decision-making process based on the fulfillment of specific methods regarding the choice of alternatives or probabilities, such as, for example, the axiom of "the exclusion of non-feasible alternatives" (Vidal 2012, p.144).

The omission of some alternatives and transparent information on the available options keeps the decision-making process clear as the available options are known to facilitate an environment of knowledge during the decision-making (Aguiar, 2004). This is a controversial aspect pointed out by León (1987), cited by Páez (2015), whose argument is based on strict compliance with the regulatory model. 
This author bases his approach of non-reality of the regulatory paradigm fulfillment in the decision environment on questioning whether the application of formal axioms is fulfilled in the decisive process; whether there is an interaction between human logic and the structured method; and on the aspect of the possibilities presented in numerical form. The controversial and critical perspective that questions the inflexibility of the norm and the static structure of the normative paradigm versus the real aspect of the decision process is influenced by the personal perceptions of the decision-maker that guide towards the prescriptive paradigm (Páez 2015, p.857).

\section{Prescriptive Paradigm}

The prescriptive aspect, as a consequence of the controversy highlighted in the regulatory paradigm, implies taking into account the sequence of the decision-making process and its restrictions, which is explained by Simon (1983), cited by Aguiar (2004), and cited again by Páez (2015). The delineation of the process to be taken into account because of a decision-making situation, influenced by the information that an individual applies by the decision-making, compared to the formal aspect of the axiom-based regulatory character. The prescriptive paradigm that brings us closer to the concept of "practical rationality" (G. Romano 2013, p.384), where the environment and what happens in it (positive aspects and restrictive ones) have to influence through the information collected for the decision making process. The contributions of G. Romano (2013) bring the focus closer to the real practical conduct of the individual in the decision-making transition. Real functional decision-making behavior, which frames the description of the processes through which the decision-making agent undergoes, will be reviewed in the following descriptive paradigm.

\section{Descriptive Paradigm}

The descriptive paradigm deals with the profile in which decisions are taken. For this purpose, Páez (2015) states that this paradigm consists of two phases: "preparation and assessment (p. 861)". Aspects in which the context of the decision-making environment influences the decision-making process based on information from the environment, what Arocena (2012) calls the incorporation into the decision-making process of "biases and heuristics" that summarize the scenario or situation and focus the decision-making process (preparation phase).

For the second phase, the assessment phase considers the options according to the expected effectiveness (subjective aspect) and whether this effect contributes to choosing the most appropriate option for making the decision (Páez, 2015). Both phases reflect the alignment and direct influence of the immediate circumstances and the environment of these conditions that the decision-maker appreciates and analyses. What Arocena (2012) describes as emerging circumstances that appear in the background and influence the decision-makers, who apply their rational capacity, is the subject that will be reviewed below.

\section{Decision-making Rationality}

All decisions have a consequence, and in the business environment, one of the primaries expected outcomes or expected impacts is to make the organization profitable through optimal economic results, as mentioned by Fincowsky, (2011), in the environment of decision making "keeping sight of the goals to guarantee its objective" (p.120). From this perspective and to adequately visualize the nexus that will be used to align the theoretical framework of decision making with the business intelligence concept, it is shared what was conceptually contributed by the neo-Schumpeterian tendency, stated by Berumen et al. (2005).

Neo-Schumpeterian tendency, which has an economic tendency as well as the theory of rational choice (additional to its essence or psychological approach to decision making) Berumen et al. (2005) stated that the conceptual point of reference of the neo-Schumpeterian tendency studies "is based on the strong conviction that individuals are beings of bounded rationality" (p. 9).

Reference point, where subjective aspects complement the rationality degree of decision-makers, such as making judgments based on their previous experience and influenced by the environments supported 
by the information received aspect reviewed in the descriptive paradigm and its phases. In this respect, Laca (2012), referring to Elster (2003), states that essential decisions often involve endless choices" (p.124), which include influences from environmental alternatives that extend a simple rational choice in decision-making.

This reference as mentioned earlier point of the neo-Schumpeterian tendency is extended by Crew (2005), follower of the trend, towards aspects where the information of the environment aligns it with the application of the technology, by mentioning that the "possession of exclusive information or technology generates an essential advantage" intending to establish a difference in the organization which uses it. It also is supported by Laca (2012), according to the term "cognitive optics," which explains it as the alignment of environmental persuasions and the decision process that causes or uses the information and chooses the answer (p.129), which is the decision.

Considering these contributions and including the relationship between technology and the economy, which wields the neo-Schumpeterian tendency (Berumen, Arriaza and Bagnasco, 2005), where the bounded rationality of the decision-maker is aligned with the information and the technological aspect of the environment (Crew, 2005). Cognitive perspective, which in turn influences the decision-making process towards the generation of an organization's essential advantage, the following subject of the information and technology influence will be reviewed as a theoretical aspect that is a bridge towards the concept of business intelligence.

\section{Theoretical Aspect as Bridge Between Decision Making and Business Intelligence}

Taking into account the neo-Schumpeterian approach that shares the rational aspect limited to the decision-maker, which is enriched by the information regarding the circumstance and the technology developed in the environment, as stated by Crew (2005) and Laca (2012). Both concepts are considered as external enablers that create "intelligence practices" (García and Ortoll 2012, p.80), environment observation and information process which are collected "for extracting intelligence" (Fleisher and Bensoussan, 2008). Intelligence practices, which bring us closer to the origins of business intelligence, as pointed out by García and Ortoll (2012), who describe it as intelligence, which, at first, was related "in the field of environmental management" and later evolved towards "processes, technology, and information management, both internal and external" (p.79), which work together with preliminary knowledge for decision-making, as pointed out by Díaz (2007). Information that is transformed into knowledge facilitating decision making through different sources and technological methodologies that process it, such as business intelligence, a concept analyzed by Luhn (1958) in a Journal of IBM publication, referred to by Oramas (2009), which in principle was defined as "the acquisition and use of knowledge based on facts to improve business strategy" (p.42).

Having developed the theoretical framework that connects decision making with business intelligence, the next stage of the paper will focus on performing a literature review where the previous academic opinions will be shared regarding the existence of interrelation and influence links between both current business concepts, which corroborate with the theoretical framework developed.

\section{LITERATURE REVIEW}

The literature review will consist of three essential areas to focus on The first one is where the business intelligence technological tool influences the decision-making process of a global organization. The second one will be on sharing the concepts and applications of business intelligence, or the linkage between business intelligence and strategic decision making will be shared. The third one is, an approach to achieve and share competitive advantage based on accurate decisions, supported by the business intelligence technological tool.

\section{Business Intelligence}

Business Intelligence is a technological tool developed in the ' $90 \mathrm{~s}$, whose initial objective was to provide a technological structure (architecture) in order to allow fair and efficient use of both internal 
operational data and environmental data designed by organizations (Bustamante, Galvis, Gomez 2016). A clear definition of the business intelligence concept is shared by Flórez (2012), when he stated that "it consists in the process of analyzing in detail the information obtained by an organization in order to achieve an abstraction that allows generating knowledge" (p.13).

In the same coherent academic definitions line, Negash and Gray (2008) describe the business intelligence concept as a system of combinations between the data obtained with its analysis that generate valuable information both inside and outside the organization to be used by the decision-maker. The internal and external information resulting from the data abstraction becomes a valuable tool to increase the knowledge of the organization and its leaders focusing on the decision making process.

This is what Gomez and Bautista (2010), in a textual definition, describe as the "tool under which different types of organizations can support decision making based on accurate and timely information" (p.321). Definition aligned with the point of view of Ballard et al., (2006) where emphasizes the aspect of the imperative knowledge conception where, based on this generated information, it makes deciding more convenient for the success of the company and to generate competitive advantages. This is because the information is an essential intangible resource that, once processed and analyzed through technological means, contributes to the organization's basic strategy and to effective decision making.

Cohen and Asin (2005) reaffirm this contribution when they highlight the use of technological tools such as business intelligence as necessary support for processing information and generating organizationally correct decisions. The business intelligence technological tool, whose implementation within an organization generates an architecture, provides efficiency to the information and corporate data management, (Gomez and Bautista 2010).

These authors also emphasize the contribution of the business intelligence technological tool towards decision-makers executives, sharing processes (data), and accurate analysis (information) that contribute to the executive action of the decision making (knowledge).

\section{Business Intelligence and Strategic Decision-making Linkage}

The process of making an executive decision with the support and the expected success is a constant challenge in the organizational environment; even so before the complexity of the dynamic changes that often generates uncertainty. This complexity increases the degree of difficulty of the decision-maker to carry out a decision making this action successfully (the complexity increases as more variables are considered).

The authors Roldán et al. (2012), according to this greater complexity, indicate, citing Huber (1984), that this challenging environment is manifested in three interconnected dimensions that characterize the new post-industrial society (p.241). These are 1) a substantial increase in the knowledge level (evolution of information technologies that facilitate access to knowledge). 2) a substantial increase in the difficulty of knowing and anticipating the way of thinking of individuals who influence their decision-making power. 3) an increase in the variability level of the business scenario, where constant changes require being better informed in order to make timely decisions.

Aspects involving being able to be more efficient with the management of the full range of information, referring to a better management level supported by technological tools, is a scenario in which business intelligence and its use help to facilitate the administration of such management. Indeed, "it is extremely positive for effective decision making" (Pourshahid et al., 2011).

Effective decision-making consists of four phases: logical analysis, delineation, choice, and execution (Vidal, 2012). By aligning some of the business intelligence applications, it illustrates the link between the different business intelligence applications and the decision-making process referred to by the aforementioned author; it is possible to focus on the use of the dashboard for the first phase of logical analysis.

The dashboards are defined by Perez (2013) as "a computational interface with reports, charts and warning systems, which are consolidated in an information platform to obtain a clear vision of the business." In the same sense (Kaplan and Norton, 2004) indicate that these are tools that support dosage through indicators that efficiently process a large volume of information.

Journal of Applied Business and Economics Vol. 22(2) 2020151 
For the second, third, and fourth phases of the decision-making process: delineation, choice, and execution (Vidal, 2012), the use of the business analytic tools or applications is a technological instrument that proactively collaborates in these phases and that in the opinion of Davenport (2006) and Turban et al. (2011). It is a comprehensive business intelligence application that provides reporting instruments, queries, data mining, as well as evolved statistical analysis.

The application of business analytics provides a projected view of future scenarios involving the business environment in a multidimensional way that enables the data visualization and indicators that contribute to the decision-making approach based on different interrelated scenarios.

\section{Business Intelligence Applications Supporting the Decision-making Process}

In the previous topic, some applications have been listed - business intelligence components linked to the decision making process as examples; in this topic, these examples will be complemented by sharing two more business intelligence applications or components: data mining and business performance management (BPM).

These applications examples that confirm the academic contribution of Peña (2006), cited by Calzada and Abreu (2009), regarding the different applications of business intelligence, which "try to characterize a wide diversity of technologies, software platforms, specifications of applications and processes" (p.33), favoring the information channeling, generating the knowledge to decide appropriately.

\section{Data Mining as a Decision-making Enabler}

The application of business intelligence through its components, such as data mining, is a technological tool that provides essential support to decision making "by cleaning and transforming data from transactional systems and unstructured information (internal and external) into structured information" (Marcano and Talavera, 2007 p.107). Structured information is the essential input that becomes knowledge, and that provides the basis and support to the decision-maker.

The structured information helps in the analysis of diverse scenarios of business performance. It is presented in different periods comparing indicators, identifying behaviors, and projecting evolutions based on tendencies that clarify the business panorama towards decision making while minimizing the risks for obtaining optimal business economic results (Marcano and Talavera, 2007). Also described as "knowledge extraction" by Witten and Frank (2005).

The knowledge extraction based on one of the techniques within data mining as the so-called "decision trees" (Berlanga, Rubio, and Vila, 2013); authors who describe the concept as the way to visualize a decision-making action can cause possible scenarios, thus collaborating on projecting the fluidity of the relationships of the decision process, through probabilistic analysis and variables interactions, anticipating future consequences.

With the authors, as mentioned earlier, sharing and their interpretation of data mining. It is projected as a technological tool of the business intelligence branch with strategic benefits that contributes to increasing competitive levels through effective and fast decisions based on analyzed, cleaned, and processed information whose applicability generates selective knowledge.

\section{Business Performance Management System as a Decision-making Enabler}

This section - application of business intelligence is defined by Roldán, Cepeda, and Galán (2012), as "an integrated set of analytical and management processes, supported by technology, that directs financial and operational activities" (p.248). This definition combines strategic management and its goals, based on verification through key financial and operational performance indicators in a similar way.

The component of business intelligence that provides a comprehensive automated approach; modeling processes of business operations which by visualizing them through indicators, allows flexibility on the decision making with greater agility and flexibility depending on the financial goals of the organization, being this component "a support platform for management decision making" (Diaz 2008, p.152). 
Reasoning and conceptualization of a decision making support platform, which is aligned with what is shared by Garimella, Lees, and Williams (2008), as a harmonic and convergent system in which management tools, technological tools and collaborative applications optimize business processes as a support for better decision execution.

In this conceptual framework, Roldan et al. (2012), (2012), make particular reference to dashboards, an application-defined by Pérez (2013) as "a computational interface with reports, charts and warning systems that are consolidated in an information platform to obtain a clear business vision."

Based on the review performed on this topic, regarding applications, business intelligence components, there has been a desire to share the approaches of the authors, as mentioned earlier. All of these is aligned and interrelated with their contributions of technology, whose essence is both internal and external data, which, when processed become valuable information provided by the business intelligence tool towards the decisional process of a business leader, based on knowledge.

As stated by (Gomez and Bautista 2010), business intelligence collaborates by providing support and sustainability, based on cleaned and simplified analyzed information, to the decision-maker who is responsible within an organization, to differentiate in a successful way and based on his/her decisions generates value both inside and outside the organization by creating competitive advantages. Competitive advantages that will be reviewed in the following sections of this article.

\section{Competitive Advantages Based on Decision-making Supported by Business Intelligence}

The business intelligence systems as a tool to support the decision making process generates an integrating change within the organization that is reflected as a competitive advantage, integration of central areas of the organization, through the processed information generating: "financial, operational, commercial and logistical" (Roldan, et al. 2012 y Cano 2007), focus as perceptible, imperceptible and transcendental advantages.

Competitive advantages focused through the decision making process, such as cost efficiency, increases in profitability margins, time efficiency, which can be perceived as tangible and measurable aspects as a result of correct decision making. From the approach of slight advantages, Cano (2007), considers that having cleaned, selected and timely information through technological means fed by internal and external data, contributes to the effectiveness of decision making, represents a competitive advantage from an intangible point of view.

From the perspective of transcendental competitive advantages that can also be called strategic competitive advantage, the author as mentioned earlier, Cano (2007), considers that as part of this strategic spectrum, the executive decision-makers management visibility is broader, based on the contribution of value to all the organization's stakeholders and specifically to the satisfaction of the client's needs.

An aspect of strategic competitive advantage that Drucker (2004), cited by Hurtado (2008), credits to the management of the executive decision-maker who, based on information as a source of effectiveness, guides the company "on what must be done and what is best for the company" (p.59). Information processed on the basis of data and diverse sources that, cleaned and simplified, "develop agile solutions to create value" (Agarwal et al. 2015), by technological means, produce useful visual indicators to generate the logical correlational reasoning that leads knowledge towards decision making.

Ahumada and Perusquia (2014) noted that there is a direct positive relationship between competitiveness and business intelligence, concluding that such strengthening actions represent a tendency towards increased competitiveness concerning business intelligence. They also stated that business intelligence as phases or variables of the process generates competitiveness of the technologybased information technology sector. 
FIGURE 1

\section{COMPETITIVENESS VS. BUSINESS INTELLIGENCE CORRELATION CHART}

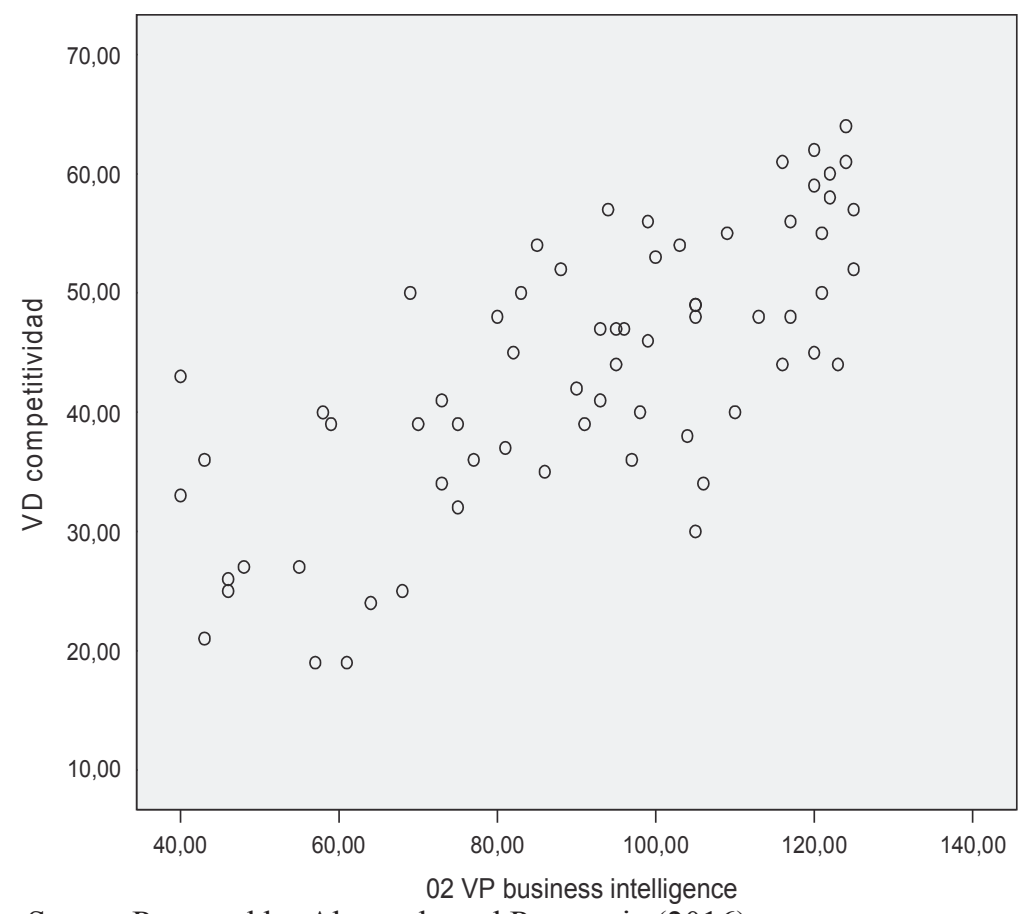

Source Prepared by Ahumada and Perusquia (2016)

\section{INFLUENCE OF BUSINESS INTELLIGENCE ON THE DECISION-MAKING PROCESS ANALYSIS}

The current executive with global vision has two alternatives to consolidate the decision-making act through the decision-making process within the current business change environment: to make programmed and emerging decisions. For both decision-making alternatives, as has been reviewed, business intelligence has a significant contribution as support to these decisions from a technological approach of data processing converted into information that contributes to the knowledge of the executive decision-maker.

Decision-making is linked to the integral and relational knowledge of the different organization areas through business intelligence in a strategically and visually transversal way to face "structures identified with a continuous change" (Marcano and Talavera 2007 p. 105), so the vision of decision making must be adaptive (programmed decisions and emerging decisions).

And at this point in the alignment of programmed decisions and emerging decisions for adapting the organization to the scenario of the dynamics of business change, where business intelligence, through its applications in continuous evolution, influences through a "decision support system" (Marcano and Talavera 2007). This is done by selecting and simplifying the process, choosing the useful data to convert them into selected information to be used in the decisional function that contributes to the central objective of the organization.

Selected and simplified information through both current and projected indicators are essential for the analysis and management of such information towards the knowledge generation that covers the expectations of adapting to the preventive vision before potential threats and opportunities (Roldan et al. 2012). To manage the uncertainty, which is the center of influence for business intelligence through its integrated approach of information and knowledge towards decision making. 
From a particular pragmatic point of view, the competitive advantage nowadays is not in possessing all the applications and evolutions of the technological business intelligence tool. It does not create a competitive advantage nor influence. The difference is in the management given to these tools through the decision-maker and the agile and optimal framework of using them in emerging scenarios (unstructured) and turning them into knowledge.

What Pourshahid et al., (2011), in a new citation, refers to as the scenario in which business intelligence collaborates and influences in facilitating the decision management, to which is added to the contribution of Oramas (2009), "to build knowledge over the business" (p. 50). By improving business competitiveness where the individual decision-maker and his/her good management and use of technology is the great influence that makes the difference in the usefulness of business intelligence as a simple technological instrument versus the appreciation of an element of decisional stability.

Ahumada and Perusquia (2014) remarked that there is a positive relationship between competitiveness and business intelligence and concluded that strengthening actions tend to increase and improve when both become stronger. The researcher notes that there is a homoscedasticity relationship because they keep a similar dispersion, as observed in the following chart.

\section{FIGURE 2}

\section{VD COMPETITVENESS: ANOVA OF COMPETITIVENESS IN TERMS OF BUSINESS INTELLIGENCE AND COMPETITIVENESS}

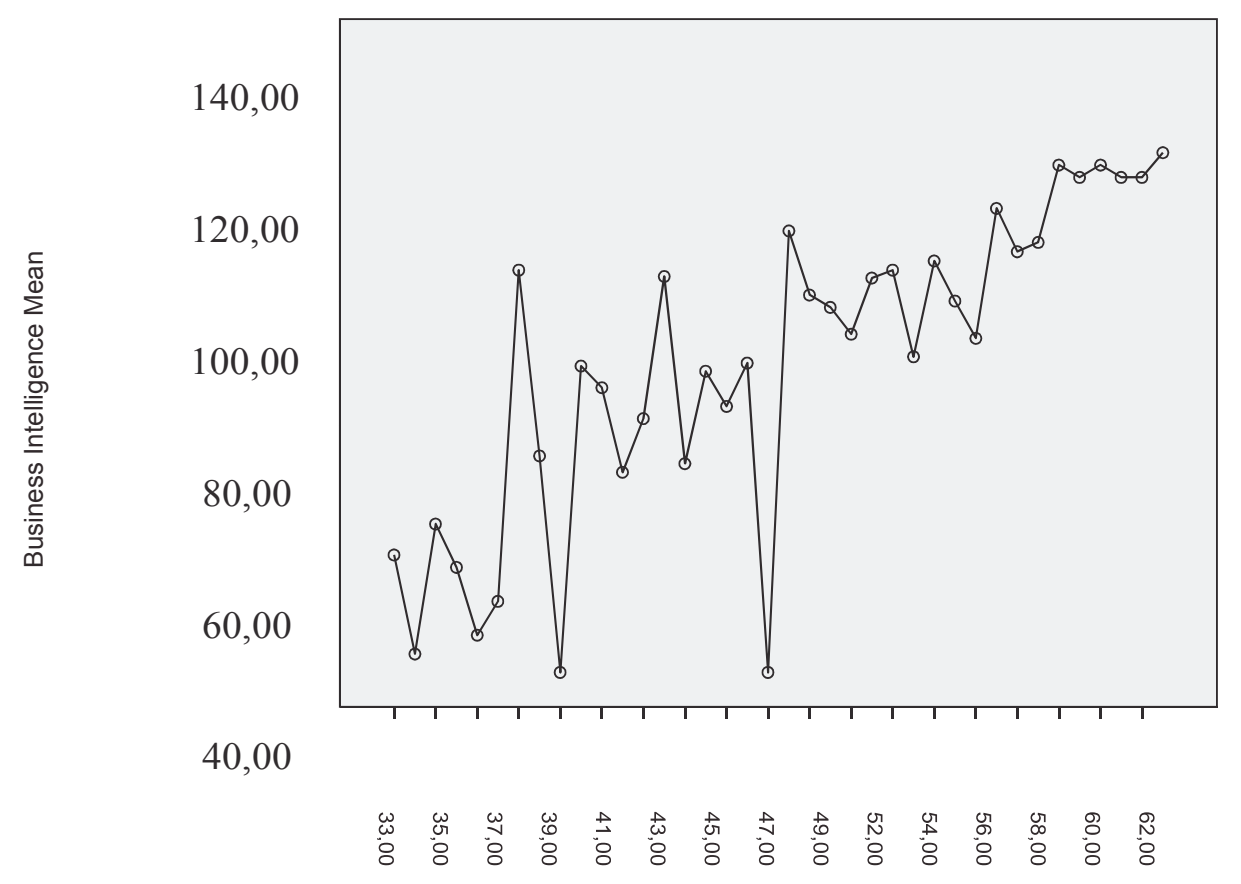

\section{CONCLUSIONS AND RECOMMENDATIONS}

The academic review of this paper shares a journey through different points of view of different authors whose convergence in its parts focuses on the importance of internal and external data collection that, after a process of synthesis and cleaning becomes specialized information to generate knowledge to the organization and to the decision-maker.

The documentary review of specialized literature, concludes that there is a high degree of interdependence, connection, and direct interrelationship of influence between business intelligence and organizational decision making in a global business environment. A conclusion that answers the question 
raised as the subject of the paper: Is there or not influence of the business intelligence technology tool in the decision-making process of a global organization?

As a recommendation for future research, taking as a theoretical basis the literature review shared in this paper, it is suggested to carry out a mixed research (quantitative and qualitative), based on gathering information from various companies of different levels and dimensions, to measure the maturity degree of this direct quantifiable influence.

\section{REFERENCES}

Agarwal, D., Rea, B., \& Berkel, A. (2015). Simplificación del trabajo: la próxima revolución. Deloitte University Press, 88-95.

Aguiar, F. (2004). Teoría de la decisión e incertidumbre: modelos normativos y descriptivos. Empira. Revista de metodología de ciencias sociales, 8, 139-160.

Ahumada, E., \& Perusquia, J. (2016). Inteligencia de negocios: Estrategia para el desarrollo de competitividad en empresas de base tecnológica. Contaduría y Administración, 61(1) , 127-158.

Arocena, F. (2012). Racionalidad limitada y gestión de riesgos en la sociedad del riesgo global. RIPS: Revista de Investigaciones Políticas y Sociológicas, 11(1), 105-118.

Ballard, C., Abdel, A., Frankus, R., Hasegawa, F., Larrechart, J., Leo, O., \& Ramos, J. (2006). Improving business performance insight with business intelligence and business process management. RedBooks, 67-123.

Berlanga, V., Rubio, M., \& Vila, R. (2013). Como aplicar arboles de decisión en SPSS. REIRE, 6(1), 6579.

Berumen, S., Arriaza, K., \& Bagnasco, F. (2005). Información y tecnología, y sus posibilidades para mejorar la competitividad de las empresas. Revista Escuela de Administración de Negocios, 53, 6-23.

Bustamante, A., Galvis, E., \& Gómez, L. (2016). Perfil de la investigación sobre inteligencia de negocios en America Latina. Revista UIS Ingenierias, 15(1), 41-51.

Calzada, L., \& Abreu, J. (2009). The impact of business intelligence tools in executive business decisions. Daena: International Journal of Good Conscience, 4(2), 16 - 52.

Cano, J. (2007). Business Intelligence: Competir con información. ESADE Business School.

Cohen, D., \& Asin, E. (2005). Sistemas de información para los negocios. México: McGraw Hill.

Crew, P. (2005). Private knowledge public profits. Oxford University Press.

Davenport, T. (2006). Competing on analytics. Harvard Business Review, 84, 98-107.

Díaz, F. (2008). Gestión de procesos de negocio BPM, TICs y crecimiento empresarial. Universidad y Empresa, 10(15), 151-176.

Díaz, L. (2007). Gestión del conocimiento y del capital intelectual: Una forma de migrar hacia empresas innovadoras, productivas y competitivas. Revista EAN, 61, 39 - 68.

Fincowsky, E. (2011). Toma de decisiones empresariales. Fondo Editorial Universidad Católica del Perú, 113-120.

Fleisher, C., \& Bensoussan, B. (2008). Business and competitive analysis: effective application of new and clasicc methods. New Jersey: Pearson Education, Inc.

Flórez, H. (2012). Business intelligence as support of decisions making in management. Vinculos, 9(2), 11-23.

García, M., \& Ortoll, E. (2012). Competitive intelligence: theory and practice. Ibersid: Revista de Sistemas de Informacion y documentacion, 6, 77-88.

Garrimella, K., Lees, M., \& Williams, B. (2008). Introducción a BPM para dummies. Indiana: Wiley Publishing, Inc.

Gartner, Inc. (2013). Hunting and harvesting in a digital world: Insights from the 2013 Garnter CIO agenda report. New York: Marketing Communications.

Gómez, A., \& Bautísta, D. (2010). Inteligencia de negocios: estado del arte. Scientia et Technica, 1(44), 321-326.

156 Journal of Applied Business and Economics Vol. 22(2) 2020 
Hurtado, F. (2008). Tratamiento de las tecnologias de inteligencia de negocios en la estrategia de TI. Revista Sistemas, (106), 57-68.

Kaplan, R., \& Norton, D. (2004). Mapas estratégicos: Convirtiendo los activos intangibles en resultados tangibles. Barcelona: Gestión 2000.

Laca, F. (2012). Racionalidad limitada en la sociedad del riesgo mundial. Revista de Economía Institucional, 14(26), 121-135.

Marcano, Y., \& Talavera, R. (2007). Mineria de datos como soporte a la toma de decisiones empresariales. Opción, 23(52), 104-118.

Miret, J. (2015). Diseño de una herramienta de BI basada en excel para el análisis de indicadores de competitividad empresarial. Doctoral Dissertation Universitat Politecnica de Valencia, 1-85.

Negash, S., \& Gray, P. (2008). Business intelligence. Handbook on decision support systems 2. Variations. In F. Burstein, \& C. Holsapple. Berlin: Springer - Verlag.

Oramas, J. (2009). La inteligencia de negocios, un concepto informático. Revista Sistemas, 42-51.

Páez, J. (2015). Teorías normativas y descriptivas de la toma de decisiones: un modelo integrador. Opción, 31, 854-865.

Pérez, A. (2013). Módulo Dashboard de BIAdviserWeb. Tésis Diploma Instituto Superior Politécnico Jose António Echevarria. La Habana.

Pourshahid, A., Richards, G., \& Amyot, D. (2011). Toward a goal - oriented, business intelligence decision - making framework. MCTECH, 100-115.

Roldán, J., Cepeda, G., \& Galán, J. (2015). Los sistemas de inteligencia de negocio como soporte a los procesos de toma de decisión en las organizaciones. ResearchGate, 239-260.

Romano, G. (2013). Acerca de la condicion normativa de la teoría de la decisión racional. Cuadernos de Economía, 32(60), 375-398.

Taylor, D. (2013). Decision making and problem solving 1. Handbook of organizations, 20, 48-86.

Turbán, E., Sharda, R., \& Delen, D. (2011). Decision support and business intelligence systems. New Jersey: Prentice Hall.

Vidál, J. (2012). Teoría de la decisión: proceso de interacciones u organizaciones como sistema de decisiones. Cinta de Moebio, (44), 136-152.

Witten, I., \& Frank, E. (2005). Data Mining: Practical machine learning tools and techniques. Morgan Kaufmann. 